\title{
Smoking and alcohol drinking increased the risk of esophageal cancer among Chinese men but not women in a high-risk population
}

\author{
Ming Wu $\cdot$ Jin-Kou Zhao $\cdot$ Zuo-Feng Zhang $\cdot$ Ren-Qiang Han $\cdot$ Jie Yang $\cdot$ \\ Jin-Yi Zhou $\cdot$ Xu-Shan Wang $\cdot$ Xiao-Feng Zhang • Ai-Min Liu $\cdot$ Pieter van' t Veer • \\ Frans J. Kok $\cdot$ Ellen Kampman
}

Received: 25 September 2010/Accepted: 25 January 2011/Published online: 15 February 2011

(C) The Author(s) 2011. This article is published with open access at Springerlink.com

\begin{abstract}
Although the association for esophageal cancer with tobacco smoking and alcohol drinking has been well established, the risk appears to be less strong in China. To provide more evidence on the effect of smoking and alcohol consumption with esophageal cancer in China, particularly among Chinese women, a population-based case-control study has been conducted in Jiangsu, China, from 2003 to 2007. A total of 1,520 cases and 3,879 controls were recruited. Unconditional multivariate logistic regression analysis was applied. Results showed that the odds ratio (OR) and confidence interval (CI) for ever smoking and alcohol drinking were 1.57 (95\% CI: $1.34-1.83)$ and 1.50 (95\% CI: 1.29-1.74). Dose-response relationships were observed with increased intensity and longer duration of smoking/drinking. Risk of smoking and alcohol drinking at the highest joint level was 7.32 (95\% CI: 4.58-11.7), when compared to those never smoked and
\end{abstract}

M. Wu (凹) · J.-K. Zhao · R.-Q. Han · J. Yang · J.-Y. Zhou Jiangsu Provincial Center for Disease Control and Prevention, No. 172 Jiangsu Road, Nanjing, Jiangsu 210009, China e-mail: jswuming@vip.sina.com

M. Wu · P. van' t Veer · F. J. Kok · E. Kampman Division of Human Nutrition, Wageningen University, Wageningen, The Netherlands

Z.-F. Zhang

Department of Epidemiology, School of Public Health, University of California, Los Angeles, CA, USA

X.-S. Wang · X.-F. Zhang

Ganyu Center for Disease Control and Prevention, Ganyu, Jiangsu, China

A.-M. Liu

Dafeng Center for Disease Control and Prevention,

Dafeng, Jiangsu, China never drank alcohol. Stratifying by genders, smoking and alcohol drinking increased the risk among men with an OR of 1.74 (95\% CI: 1.44-2.09) and 1.76 (95\% CI: 1.48 2.09); however, neither smoking nor alcohol consumption showed a significant association among women. In conclusion, smoking and alcohol drinking were associated with esophageal cancer risk among Chinese men, but not among Chinese women.

Keywords Esophageal cancer - Smoking - Alcohol . Case-control studies · China

\section{Introduction}

Esophageal cancer remains one of the most fatal malignancies in the world. In 2005, about 497,700 new cases occurred worldwide, and the prevalence is expected to increase by approximately $140 \%$ by 2025 [1]. The actual etiology of esophageal cancer remains unclear, but extensive evidence in the past decades has demonstrated that tobacco smoking and alcohol drinking are prominent risk factors of this disease [2-6]. The risk of esophageal cancer among smokers is $2-5$ fold in general when compared to non-smokers, while for heavy smokers, the risk may exceed tenfold [3]. The average risk of esophageal cancer with alcohol drinking is estimated to be 1.04 -fold per drink/week [4], and the risk ratio may also over tenfold among heavy drinkers [5]. Some previous studies reported that the associations significantly increased when alcohol and smoking coexist, their joint effects are approximately multiplicative and may increase 130 -fold in the highest joint level [6].

Although the association for esophageal cancer with tobacco smoking and alcohol drinking has been well 
established in many areas of the world, some striking variation between regions does exist [2]. In Western countries, smoking and alcohol consumption seem to be the primary risk factors of esophageal squamous cell cancer, the population attributable fraction (PAF) of smoking and alcohol was estimated to be 71 and $41 \%$, respectively [7]. China is an area with one of the highest incidence of esophageal cancer worldwide, about half of the cases that occur in the world each year are estimated to be in this country [8]. Whereas, the strong association of smoking and alcohol as well as their multiplicative joint effects were observed considerably weaker or even absent according to some previous studies [9-12]. The proportion of esophageal cancer attributed to smoking and alcohol in China was estimated to be only 23 and $16 \%$, respectively [13]. Previous studies showed that smoking and alcohol are strong and important risk factors in both genders in Western populations [5, 14-16]; however, because of the rather low prevalence of smoking and alcohol drinking in Chinese women, very few studies explored the etiology of these two risk factors among women in this country.

During 2003-2007, a large population-based case-control study on esophageal cancer has been carried out in Jiangsu province, an area with the third highest esophageal cancer mortality in China [17]. The study design has previously been described in detail $[18,19]$. In brief, this study was conducted in two counties, Dafeng and Ganyu. Both of these counties are less-developed rural areas in northern Jiangsu, and farming remains the main occupation of the local population. The annual average age-standardized incidence during $2006-2008$ by China standard population was 36 and 24 per 100,000 in Dafeng and Ganyu, respectively. In this present analysis, we analyzed the overall and gender-specific effects of smoking and alcohol drinking on esophageal cancer in this high-risk Chinese population. It aims to provide further data on the independent and joint effects of these two well-known risk factors in China, especially among Chinese women.

\section{Materials and methods}

\section{Subject recruitment and data collection}

Eligible subjects were restricted to local inhabitants who have lived in the study area for at least 5 years. Newly diagnosed primary esophageal cancer patients were recruited as cases, using the data from local populationbased cancer registries. From 2003 to 2007, 68 and $75 \%$ of all newly registered patients were recruited and interviewed in Dafeng and Ganyu, respectively. Because of the low proportion of pathological examination in the less-developed rural areas (39\%), patients who were diagnosed by other sophisticated methods such as endoscopic examination $(40 \%)$ or radiology $(11 \%)$ were also included.

Controls were derived from the same county as cases, randomly selected from the county demographic database. Controls were frequency matched with cases by gender and age ( \pm 5 years). The participation rate of controls was $87 \%$ in Dafeng and $85 \%$ in Ganyu, respectively.

With written informed consent, epidemiological data were obtained by face-to-face interviews using a pre-tested standardized questionnaire. The questionnaire included detailed information on factors known or suspected to be associated with esophageal cancer, including demographic information, socio-economic status, living conditions, environmental exposures, and dietary habits. Details on lifetime smoking and alcohol drinking habits were collected, questions included age at starting smoking/drinking, years of consumption, the average number of cigarettes smoked per day, weekly frequency, and the amount of drinking different types of alcohol beverages (e.g., beer, wine, and liquor). If the subject had quit smoking/drinking habit at time of interview, the duration of cessation was also recorded. This study was approved by the Institutional Review Board of the Jiangsu Provincial Health Department.

\section{Statistical analysis}

In the present analysis, never smokers were defined as having smoked fewer than 100 cigarettes in their lifetime; while never drinkers were those who drank less than once per month. Current smokers and current drinkers were defined as those who had the habit at the time of interview or stopped the habit within 1 year before interview. Packyears of smoking and weekly consumption of pure ethanol (grams/week) on average were calculated. Since no marked difference was observed regarding the effect of smoking and alcohol drinking between the two counties, data were pooled to improve statistical power.

Confounders were selected based on the previous knowledge on esophageal cancer and our preliminary results [20], including age, gender, education level, previous income, body mass index (using Chinese recommendation standard) [21], family history of cancer in firstdegree relatives (any malignancy), and study area. After adjusting for confounders, the overall and gender-specific effects for smoking and alcohol drinking were evaluated by unconditional logistic regression. The strength was quantified as odds ratios (OR), and 95\% confidence intervals (CI) around the OR were used to quantify precision. The trend test of ordered variables was performed by assigning scores to different exposure levels and treating the categorical variable as a continuous variable in the logistic regression model. Effect modifications were evaluated by 
stratification, statistical interaction was assessed by including main effect variables and their product terms in the logistic regression model.

Data were entered into the computer by Epidata 3.0, cleaned and analyzed using SAS v9.1 software (SAS Institute, Inc., Cary, NC).

\section{Results}

In total, 1,520 cases (637 in Dafeng and 883 in Ganyu) and 3,879 controls (1,938 in Dafeng and 1,941 in Ganyu) were recruited. Table 1 shows the demographical information and socio-economic characteristics of cases and controls by gender. Cases were more frequently men and older people and more frequently occurred in the population with lower socio-economic status, i.e., lower education level, lower previous income, lower BMI, and with cancer-affected relatives.

Table 2 shows the associations for esophageal cancer with selected smoking-related variables. Ever smoking significantly increased the risk of esophageal cancer with an OR of 1.57 (95\% CI: 1.34-1.83) compared to never smokers. ORs for former smoking and current smoking were 1.74 (95\% CI: 1.38-2.21) and 1.54 (95\% CI: 1.31-1.80), respectively. Positive dose-response relationships were observed with increased daily amount, duration, and packyears of smoking (for trend, $p<0.001$ each), except for age at starting the habit. Quitting smoking was found associated with a decreased cancer risk, OR for those who had quit for more than 10 years was similar to never smokers (OR $=0.90,95 \%$ CI: 0.62-1.30); however, quitting less than 5 years still increased risk 1.64-fold when compared to never smokers. Stratifying for gender, OR for ever smoking

Table 1 The demographic information and socio-economic status of cases and controls

\begin{tabular}{|c|c|c|c|c|}
\hline & \multicolumn{2}{|l|}{ Men } & \multicolumn{2}{|l|}{ Women } \\
\hline & Case $(\%)(n=1,191)$ & Control $(\%)(n=2,916)$ & Case $(\%)(n=329)$ & Control $(\%)(n=963)$ \\
\hline \multicolumn{5}{|l|}{ Study area } \\
\hline Dafeng & $426(35.8)$ & $1,368(46.9)$ & $211(64.1)$ & $570(59.2)$ \\
\hline Ganyu & $765(64.2)$ & $1,548(53.1)$ & $118(58.1)$ & $393(40.8)$ \\
\hline \multicolumn{5}{|l|}{ Age (years) } \\
\hline Mean (SD) & $65.3(9.6)$ & $64.2(11.0)$ & $67.4(9.1)$ & $64.9(11.7)$ \\
\hline$<60$ & $344(28.9)$ & $945(32.4)$ & $56(17.0)$ & $274(28.5)$ \\
\hline $60-$ & $405(34.0)$ & $933(32.0)$ & $142(43.2)$ & $311(32.3)$ \\
\hline $70-$ & $366(30.7)$ & $857(29.4)$ & $99(30.1)$ & $300(31.2)$ \\
\hline$\geq 80$ & $76(6.4)$ & $181(6.2)$ & $32(9.7)$ & $78(8.1)$ \\
\hline \multicolumn{5}{|l|}{ Education level $^{\mathrm{a}}$} \\
\hline Illiteracy & $608(51.1)$ & $1,302(44.7)$ & $288(87.5)$ & $755(78.4)$ \\
\hline Primary school & $409(34.4)$ & $1,028(35.3)$ & $35(10.6)$ & $142(14.8)$ \\
\hline Middle school and above & $173(14.5)$ & $584(20.0)$ & $6(1.8)$ & $66(6.8)$ \\
\hline \multicolumn{5}{|l|}{ Previous income $(\mathrm{RMB})^{\mathrm{a}}$} \\
\hline$<1,000$ & $364(31.0)$ & $691(24.0)$ & $97(29.7)$ & $207(22.0)$ \\
\hline $1,000 \sim$ & $250(21.3)$ & $541(18.8)$ & $63(19.3)$ & $206(21.9)$ \\
\hline $1,500 \sim$ & $305(26.0)$ & $764(26.6)$ & $92(28.1)$ & 269 (28.6) \\
\hline$\geq 2,500$ & $254(21.7)$ & $882(30.6)$ & $75(22.9)$ & $260(27.6)$ \\
\hline \multicolumn{5}{|l|}{ Body mass index $(\mathrm{BMI})^{\mathrm{a}, \mathrm{b}}$} \\
\hline Mean (SD) & $21.7(3.7)$ & $22.8(5.4)$ & $21.3(4.7)$ & $22.7(3.5)$ \\
\hline $18.5 \sim 23.9$ & $843(71.4)$ & $1,954(67.2)$ & $174(53.0)$ & $539(56.3)$ \\
\hline$<18.5$ & $153(13.0)$ & $186(6.4)$ & $87(26.5)$ & $92(9.6)$ \\
\hline $24 \sim 27.9$ & 149 (12.6) & $638(21.9)$ & $49(14.9)$ & $264(27.6)$ \\
\hline$\geq 28$ & $36(3.0)$ & $132(4.5)$ & $18(5.5)$ & $63(6.6)$ \\
\hline \multicolumn{5}{|l|}{ Family history of cancer } \\
\hline No & $865(72.6)$ & $2,243(76.9)$ & $212(64.4)$ & 689 (71.6) \\
\hline Yes & $326(27.4)$ & $673(23.1)$ & $117(35.6)$ & $274(28.4)$ \\
\hline
\end{tabular}

${ }^{a}$ Sum does not add up because of missing values

${ }^{\mathrm{b}}$ Chinese recommendation standard was used for the cutoff points of overweight and obesity [21] 
Table 2 The OR and 95\% CI for smoking-related variables with esophageal cancer among men and women

\begin{tabular}{|c|c|c|c|c|c|c|}
\hline & \multicolumn{2}{|c|}{ ALL } & \multicolumn{2}{|c|}{ Men } & \multicolumn{2}{|c|}{ Women } \\
\hline & $\begin{array}{c}\text { Case/ } \\
\text { Control }\end{array}$ & OR $(95 \% \mathrm{Cl})^{\mathrm{a}}$ & $\begin{array}{c}\text { Case/ } \\
\text { Control }\end{array}$ & OR $(95 \% \mathrm{CI})^{\mathrm{b}}$ & $\begin{array}{c}\text { Casel } \\
\text { Control }\end{array}$ & OR $(95 \% \mathrm{Cl})^{\mathrm{b}}$ \\
\hline \multicolumn{7}{|l|}{ Smoking status } \\
\hline Never smoking & $415 / 1,549$ & 1.00 (referent) & $187 / 824$ & 1.00 (referent) & $228 / 725$ & 1.00 (referent) \\
\hline Ever smoking & $1,105 / 2,330$ & $1.57(1.34-1.83)$ & $1,004 / 2,092$ & $1.74(1.44-2.09)$ & $101 / 238$ & $1.13(0.83-1.54)$ \\
\hline Former & $162 / 337$ & $1.74(1.38-2.21)$ & $142 / 287$ & $2.01(1.53-2.63)$ & $20 / 50$ & $1.15(0.65-2.02)$ \\
\hline Current & $943 / 1,993$ & $1.54(1.31-1.80)$ & $862 / 1,805$ & $1.69(1.40-2.05)$ & $81 / 188$ & $1.13(0.81-1.57)$ \\
\hline \multicolumn{7}{|c|}{ Daily amount of smoking (Cig/day) } \\
\hline Never smoking & $415 / 1,549$ & 1.00 (referent) & $187 / 824$ & 1.00 (referent) & $228 / 725$ & 1.00 (referent) \\
\hline$<10$ & $373 / 803$ & $1.35(1.12-1.63)$ & $338 / 718$ & $1.42(1.14-1.77)$ & $35 / 85$ & \\
\hline $10-$ & $231 / 543$ & $1.52(1.24-1.88)$ & $187 / 472$ & $1.58(1.24-2.01)$ & $44 / 71-$ & F $1.37(0.97-1.94)$ \\
\hline $20-$ & $370 / 807$ & $1.63(1.35-1.97)$ & $351 / 736$ & $1.87(1.50-2.32)$ & $19 / 71-$ & (1) \\
\hline $30-$ & $131 / 177$ & $2.84(2.16-3.74)$ & $128 / 166$ & $3.25(2.41-4.37)$ & $3 / 11-$ & $0.10(0.42-1.18)$ \\
\hline$P$ for trend & & $<0.001$ & & $<0.001$ & & 0.693 \\
\hline \multicolumn{7}{|c|}{ Duration of Smoking (years) } \\
\hline Never smoking & $415 / 1,549$ & 1.00 (referent) & $187 / 824$ & 1.00 (referent) & $228 / 725$ & 1.00 (referent) \\
\hline$<20$ & $151 / 361$ & $1.50(1.18-1.90)$ & $132 / 323$ & $1.60(1.22-2.09)$ & $19 / 38^{-}$ & \\
\hline $20-$ & $282 / 594$ & $1.70(1.39-2.08)$ & $256 / 528$ & $1.87(1.48-1.79)$ & $26 / 66$ & - $1.23(0.81-1.84)$ \\
\hline $35-$ & $419 / 855$ & $1.61(1.34-1.93)$ & $386 / 776$ & $1.80(1.45-2.22)$ & $33 / 79^{-}$ & \\
\hline $50-$ & $253 / 520$ & $1.40(1.13-1.75)$ & $230 / 465$ & $1.59(1.24-2.05)$ & $23 / 55$ & $05(0.71-1.54)$ \\
\hline$P$ for trend & & $<0.001$ & & $<0.001$ & & 0.782 \\
\hline \multicolumn{7}{|c|}{ Pack-years of smoking } \\
\hline Never smoking & $415 / 1,549$ & 1.00 (referent) & $187 / 824$ & 1.00 (referent) & $228 / 725$ & 1.00 (referent) \\
\hline$<15$ & $406 / 904$ & $1.38(1.15-1.66)$ & $362 / 805$ & $1.45(1.17-1.80)$ & $44 / 99$ & \\
\hline $15-$ & $208 / 502$ & $1.45(1.17-1.80)$ & $178 / 437$ & $1.56(1.22-2.00)$ & $30 / 65$ & $-1.20(0.84-1.72)$ \\
\hline $30-$ & $241 / 463$ & $1.85(1.49-2.29)$ & $223 / 422$ & $2.05(1.62-2.61)$ & $18 / 41-$ & \\
\hline $45-$ & $250 / 461$ & $1.91(1.54-2.37)$ & $241 / 428$ & $2.21(1.74-2.80)$ & $9 / 33-$ & $-0.95(0.58-1.56)$ \\
\hline$P$ for trend & & $<0.001$ & & $<0.001$ & & 0.765 \\
\hline \multicolumn{7}{|c|}{ Age at starting smoking (years) } \\
\hline $30-$ & $211 / 447$ & 1.00 (referent) & $164 / 353$ & 1.00 (referent) & $47 / 94-$ & \\
\hline $25-$ & $184 / 381$ & $1.24(1.00-1.53)$ & $174 / 357$ & $1.23(0.99-1.54)$ & $10 / 24-$ & nt) \\
\hline $20-$ & $373 / 780$ & $1.26(1.07-1.49)$ & $358 / 727$ & $1.30(1.09-1.55)$ & $15 / 53$ & \\
\hline$<20$ & $244 / 547$ & $1.23(1.02-1.49)$ & $219 / 490$ & $1.28(1.04-1.58)$ & $25 / 57-$ & $0.71(0.43-1.18)$ \\
\hline$P$ for trend & & 0.752 & & 0.998 & & 0.189 \\
\hline \multicolumn{7}{|c|}{ Time since stopping smoking (years) } \\
\hline Never smoker & $415 / 1,549$ & 1.00 (referent) & $187 / 824$ & 1.00 (referent) & $228 / 725$ & 1.00 (referent) \\
\hline $10-$ & $41 / 130$ & $0.90(0.62-1.30)$ & $33 / 107$ & $0.92(0.61-1.39)$ & $8 / 23$ & \\
\hline $5-$ & $41 / 81$ & $1.33(0.90-1.97)$ & $35 / 70$ & $1.34(0.87-2.05)$ & $6 / 11$ & $-1.20(0.68-2.14)$ \\
\hline$<5$ & $80 / 126$ & $1.64(1.21-2.20)$ & $74 / 110$ & $1.70(1.24-2.33)$ & $6 / 16-$ & \\
\hline$P$ for trend & & $<0.001$ & & $<0.001$ & & 0.524 \\
\hline
\end{tabular}

men and women was 1.74 (95\% CI: 1.44-2.09) and 1.13 (95\% CI: 0.83-1.54), respectively. Results showed that the magnitude of the effects among women was much smaller than the corresponding ones among men, and all associations were observed not statistically significant.

Table 3 presents the overall and gender-specific OR and 95\% CI for esophageal cancer with selected alcohol-related variables. Ever drinking alcohol significantly increased cancer risk $(\mathrm{OR}=1.50,95 \% \mathrm{CI}$ : 1.29-1.74), and ORs were observed positively associated with increased drinking frequency, longer duration, and high weekly consumption of alcohol (for trend, $p<0.001$ each), but not for age at starting drinking. A substantially elevated OR was found among former drinkers $(\mathrm{OR}=5.16,95 \% \mathrm{CI}$ : 4.23-6.29), even those who had quit drinking for more than 10 years still had a 1.80 -fold risk (95\% CI: $1.14-2.85$ ) when compared to never drinkers. Similar to smoking, the associations for alcohol consumption were found generally lower among women than that of men, OR for ever drinking was 1.76 (95\% CI: 1.48-2.09) for men but was 0.82 (95\% CI: 0.59-1.16) for women, and no doseresponse association was observed among women.

The joint effects of ever smoking and ever drinking alcohol on esophageal cancer are shown in Table 4. Although no significantly increased OR was observed for ever exposed to either smoking $(\mathrm{OR}=1.20,95 \% \mathrm{CI}$ : 0.96-1.51) or alcohol ( $\mathrm{OR}=1.03,95 \% \mathrm{CI}$ : $0.80-1.32)$ alone, being exposed to both factors increased risk 2.10fold (95\% CI: 1.72-2.56) when compared to never smoking and drinking group, with a more than multiplicative interaction $(p<0.001)$. Gender-specific results showed that either smoking or drinking alcohol alone significantly increased the risk among men, but not among women. OR for ever smoking and drinking was 2.75 (95\% CI: 2.07-3.65) for men but was 1.03 (95\% CI: 0.68-1.56) for women. No significant interaction term was observed for either men or women on a multiplicative scale. 
Table 3 The OR and 95\% CI for alcohol-related variables with esophageal cancer among men and women

\begin{tabular}{|c|c|c|c|c|c|c|}
\hline & \multicolumn{2}{|c|}{ ALL } & \multicolumn{2}{|c|}{ Men } & \multicolumn{2}{|c|}{ Women } \\
\hline & $\begin{array}{c}\text { Case/ } \\
\text { Control }\end{array}$ & OR $(95 \% \mathrm{Cl})^{a}$ & $\begin{array}{c}\text { Case/ } \\
\text { Control }\end{array}$ & OR $(95 \% \mathrm{Cl})^{b}$ & $\begin{array}{l}\text { Case/ } \\
\text { Control }\end{array}$ & OR $(95 \% \mathrm{Cl})^{b}$ \\
\hline \multicolumn{7}{|l|}{ Alcohol drinking } \\
\hline Never drinking & $490 / 1,631$ & 1.00 (referent) & $221 / 864$ & 1.00 (referent) & $269 / 767$ & 1.00 (referent) \\
\hline Ever drinking & $1,030 / 2,248$ & $1.50(1.29-1.74)$ & $970 / 2,052$ & $1.76(1.48-2.09)$ & $60 / 196$ & $0.82(0.59-1.16)$ \\
\hline Former & $454 / 293$ & $5.16(4.23-6.29)$ & $424 / 256$ & $6.43(5.14-8.04)$ & $30 / 37$ & $2.19(1.30-3.71)$ \\
\hline Current & $576 / 1,955$ & $0.94(0.80-1.10)$ & $546 / 1,796$ & $1.10(0.92-1.33)$ & $30 / 159$ & $0.52(0.34-1.02)$ \\
\hline \multicolumn{7}{|c|}{ Frequency of drinking } \\
\hline Never drinking & $490 / 1,631$ & 1.00 (referent) & $221 / 864$ & 1.00 (referent) & $269 / 767$ & 1.00 (referent) \\
\hline Occasionally & $281 / 727$ & $1.32(1.09-1.59)$ & $259 / 631$ & $1.60(1.29-1.99)$ & $22 / 96$ & $0.62(0.38-1.02)$ \\
\hline Often & $278 / 574$ & $1.70(1.40-2.06)$ & $259 / 501$ & $1.94(1.56-2.42)$ & $19 / 46$ & $1.14(0.64-2.03)$ \\
\hline Every day & $471 / 974$ & $1.54(1.29-1.84)$ & $452 / 920$ & $1.77(1.45-2.15)$ & $19 / 54$ & $0.94(0.54-1.65)$ \\
\hline$P$ for trend & & $<0.001$ & & $<0.001$ & & 0.674 \\
\hline \multicolumn{7}{|c|}{ Duration of drinking (years) } \\
\hline Never drinking & $490 / 1,631$ & 1.00 (referent) & $221 / 864$ & 1.00 (referent) & $269 / 767$ & 1.00 (referent) \\
\hline$<20$ & $102 / 314$ & $1.04(0.81-1.34)$ & $85 / 252$ & $1.27(0.94-1.70)$ & $17 / 62$ & \\
\hline $20-$ & $181 / 476$ & $1.16(0.94-1.44)$ & $168 / 436$ & $1.31(1.03-1.67)$ & $13 / 40$ & $0.83(0.53-1.29)$ \\
\hline $30-$ & $271 / 565$ & $1.36(1.12-1.63)$ & $260 / 532$ & $1.56(1.26-1.93)$ & $11 / 33-$ & $1-075(046-123)$ \\
\hline $40-$ & $414 / 812$ & $1.30(1.10-1.54)$ & $401 / 765$ & $1.57(1.29-1.91)$ & $13 / 47$ & $-0.75(0.46-1.23)$ \\
\hline$P$ for trend & & $<0.001$ & & $<0.001$ & & 0.204 \\
\hline \multicolumn{7}{|c|}{ Ethanol intake (ml/Week) } \\
\hline 0 & $624 / 1,929$ & 1.00 (referent) & $343 / 1,121$ & 1.00 (referent) & $281 / 808$ & 1.00 (referent) \\
\hline $1-$ & $125 / 331$ & $1.21(0.96-1.53)$ & $106 / 267$ & $1.37(1.05-1.79)$ & $19 / 64$ & \\
\hline $250-$ & $198 / 519$ & $1.19(0.97-1.45)$ & $182 / 466$ & $1.29(1.04-1.60)$ & $16 / 53$ & $0.79(0.46-1.36)$ \\
\hline $500-$ & $204 / 478$ & $1.30(1.06-1.59)$ & $197 / 456$ & $1.37(1.11-1.69)$ & $7 / 22$ & \\
\hline $750-$ & $354 / 562$ & $1.90(1.58-2.28)$ & $349 / 550$ & $1.96(1.62-2.38)$ & $5 / 12$ & $-0.92(0.57-1.46)$ \\
\hline$P$ for trend & & $<0.001$ & & $<0.001$ & & 0.898 \\
\hline \multicolumn{7}{|c|}{ Age at start drinking (years) } \\
\hline $30-$ & $391 / 895$ & 1.00 (referent) & $347 / 770$ & 1.00 (referent) & $44 / 125$ & \\
\hline $25-$ & $244 / 447$ & $1.45(1.20-1.75)$ & $239 / 430$ & $1.46(1.20-1.77)$ & $5 / 17$ & 1.00 (referent) \\
\hline $20-$ & $280 / 652$ & $1.25(1.05-1.49)$ & $273 / 621$ & $1.28(1.07-1.54)$ & $7 / 31$ & \\
\hline$<20$ & $104 / 231$ & $1.24(0.96-1.61)$ & $102 / 215$ & $1.33(1.02-1.74)$ & $2 / 16$ & $50.54(0.22-1.35)$ \\
\hline$P$ for trend & & 0.966 & & 0.739 & & 0.190 \\
\hline \multicolumn{7}{|c|}{ Time since stopping drinking (years) } \\
\hline Never drinking & $490 / 1,631$ & 1.00 (referent) & $221 / 864$ & 1.00 (referent) & $269 / 767$ & 1.00 (referent) \\
\hline $10-$ & $32 / 502$ & $1.80(1.14-2.85)$ & $32 / 43$ & $2.26(1.40-3.63)$ & $0 / 7$ & \\
\hline 5- & $27 / 35$ & $2.22(1.32-3.75)$ & $26 / 32$ & $2.33(1.36-4.02)$ & $1 / 3$ & $-1.66(0.79-3.49)$ \\
\hline$<5$ & $237 / 13$ & $5.28(4.19-6.65)$ & $223 / 122$ & $5.46(4.29-6.96)$ & $14 / 10$ & \\
\hline$P$ for trend & & $<0.001$ & & $<0.001$ & & 0.184 \\
\hline
\end{tabular}

Missing data were excluded from the analysis

a Adjusted for age (continuous), gender, study area, previous income (continuous), BMI (continuous), pack-years of smoking (continuous), and family history of cancer

b Adjusted for above-mentioned variables except gender

Table 5 summarized the joint effects for different levels of daily smoking and average weekly ethanol intake, while gender-specific results were not estimated, given the few numbers in some categories. Among never smokers, light or moderate ethanol intake $(<500 \mathrm{ml} /$ week) was not found to increase the risk of esophageal cancer, an elevated OR was observed for heavy drinkers ( $\geq 500 \mathrm{ml} /$ week) but did not reach statistical significance $(\mathrm{OR}=1.38,95 \% \mathrm{CI}$ : 0.97-1.98). On the other hand, among those who described themselves as never drinkers, even a low daily smoking amount $(<10 \mathrm{cig} /$ day) increased risk 1.40 -fold $(95 \% \mathrm{CI}$ : 1.07-1.83). Those who smoked more than $40 \mathrm{cig} /$ day have a 2.45-fold risk (95\% CI: 1.20-4.96) even without drinking alcohol (for trend $p<0.001$ ). Apparent positive doseresponse relationships were observed for most levels of smoking intensity and amount of alcohol intake. A significant interaction was observed on multiplicative scale $(p=0.016)$, OR for exposed to the highest level of smoking and alcohol consumption was 7.32 (95\% CI:
4.58-11.7), when compared to those who never smoked and never drank alcohol.

\section{Discussion}

In this large population-based case-control study, we confirmed that tobacco smoking and alcohol drinking were associated with esophageal cancer development in a highrisk Chinese population and found the positive doseresponse trends with both intensity and duration of consumption during lifetime. In agreement with some previous studies in China, their independent and joint effects seem to be less strong when compared to that of Western countries [9-13]. Whereas, neither smoking nor alcohol drinking was found to be associated with esophageal cancer among Chinese women in the present analysis.

Tobacco smoking and alcohol have been claimed as strong risk factors of esophageal cancer for a long time, 
Table 4 The joint effects of smoking and alcohol drinking on esophageal cancer among men and women

\begin{tabular}{|c|c|c|c|c|c|c|c|}
\hline \multirow[t]{2}{*}{ Smoking } & \multirow[t]{2}{*}{ Alcohol } & \multicolumn{2}{|l|}{ All } & \multicolumn{2}{|l|}{ Men } & \multicolumn{2}{|l|}{ Women } \\
\hline & & Case/control & OR $(95 \% \mathrm{CI})^{\mathrm{a}}$ & Case/control & OR $(95 \% \mathrm{CI})^{\mathrm{b}}$ & Case/control & OR $(95 \% \mathrm{CI})^{\mathrm{b}}$ \\
\hline Never & Never & 276/984 & 1.00 (referent) & $69 / 358$ & 1.00 (referent) & $207 / 626$ & 1.00 (referent) \\
\hline Never & Ever & $139 / 565$ & $1.03(0.80-1.32)$ & $118 / 466$ & $1.41(1.00-1.98)$ & $21 / 99$ & $0.63(0.38-1.05)$ \\
\hline Ever & Never & $214 / 647$ & $1.20(0.96-1.51)$ & $152 / 506$ & $1.48(1.06-2.05)$ & $62 / 141$ & $1.04(0.73-1.49)$ \\
\hline Ever & Ever & $891 / 1,683$ & $2.10(1.72-2.56)$ & $852 / 1,586$ & $2.75(2.07-3.65)$ & $39 / 97$ & $1.03(0.68-1.56)$ \\
\hline$P$ for interaction & & & $<0.001$ & & 0.170 & & 0.212 \\
\hline
\end{tabular}

${ }^{a}$ Adjusted for age (continuous), gender, study area, previous income (continuous), BMI (continuous), and family history of cancer

b Adjusted for above-mentioned variables except gender

Table 5 The overall OR and 95\% CI for independent and joint effects of smoking and alcohol drinking on esophageal cancer risk

\begin{tabular}{|c|c|c|c|c|c|}
\hline \multirow[t]{2}{*}{ Smoking (cig/day) } & \multicolumn{4}{|c|}{ Ethanol intake (ml/week) } & \multirow[t]{2}{*}{$P$ for trend } \\
\hline & Never & $1-249$ & $250-499$ & $\geq 500$ & \\
\hline Never & 1.00 & $1.04(0.68-1.59)$ & $0.98(0.64-1.51)$ & $1.38(0.97-1.98)$ & 0.043 \\
\hline $1-9$ & $1.40(1.07-1.83)$ & $1.41(0.94-2.12)$ & $1.52(1.07-2.17)$ & $1.89(1.45-2.46)$ & 0.100 \\
\hline $10-19$ & $1.50(1.10-2.04)$ & $2.51(1.53-4.10)$ & $1.89(1.27-2.82)$ & $1.85(1.35-2.55)$ & 0.238 \\
\hline $20-39$ & $1.39(1.06-1.83)$ & $1.70(0.99-2.90)$ & $1.89(1.34-2.66)$ & $2.74(2.15-3.48)$ & 0.003 \\
\hline$\geq 40$ & $2.45(1.20-4.96)$ & $2.28(0.36-14.2)$ & $2.04(0.53-7.89)$ & $7.32(4.58-11.7)$ & 0.021 \\
\hline$P$ for trend & 0.001 & 0.024 & 0.021 & $<0.001$ & $<0.001$ \\
\hline$P$ for interaction & 0.016 & & & & \\
\hline
\end{tabular}

Adjusted for age (continuous), gender, study area, previous income (continuous), BMI (continuous), and family history of cancer

both of them have been categorized into group I carcinogens (carcinogenic to human) by the working group of International Agency for Research on Cancer (IARC) [22]. Strong associations for smoking and alcohol consumption with esophageal cancer were observed in Western countries (including South-American and African populations); however, the risks appear to be much lower in China, especially in some high incidence regions [9-11]. In a large prospective study in Linxian China, one of the highest esophageal cancer risk areas in the world, Tran et al. [9] only found modest elevations in the risk of esophageal cancer among current smokers $(\mathrm{OR}=1.3)$, while alcohol drinking was not associated with esophageal cancer $(O R=0.86)$. In a meta-analysis of seven Chinese studies, the pooled OR for smoking and alcohol drinking on esophageal cancer was estimated to be 1.84 and 1.50, respectively [13]. Similarly, we observed a moderate increased risk of smoking $(\mathrm{OR}=1.57)$ and alcohol drinking $(\mathrm{OR}=1.50)$ in our study, supporting that the risks of these two well-known risk factors are less strong in China.

The reasons for the weaker association could be partly explained by the short exposure history and considerably low prevalence among Chinese women [7]. Although China is currently the largest producer and consumer of tobacco in the world and there is evidence of a striking increase in alcohol consumption, tobacco, and alcohol use became more prevalent in China just from 1980s, and traditionally, it is more acceptable for Chinese men to smoke and drink than for women. It has been reported that about $66.9 \%$ of men but only $4.2 \%$ of women are smokers in China, whereas the prevalence of smoking among men and women was estimated to be 35 and $22 \%$ in developed countries, 50 and $9 \%$ in developing countries [23, 24]. The annual ethanol consumption among Chinese adults was also reported much lower than in industrialized countries, and men drink 13.4 times more than women [25]. Another explanation for the weak association is that there might be some other strong risks factors that account for the majority of cases in those high-risk areas; thus, the effect of smoking and alcohol drinking is diluted [26]. For instance, nutrition deficiency, exposure to $\mathrm{N}$-nitrosamines, and fungi toxins have been summarized as the major causative factors in some high-risk areas of China [27].

Several studies have indicated that smoking and alcohol consumption are strong risk factors for both men and women in Western populations [5, 14-16], but very few studies explored their effects among Chinese women because of the considerably low prevalence. Gao et al. [28] reported that the risk of smoking among women was 1.6 (95\% CI: 1.0-2.4) in a case-control study (902 cases and 1,552 controls), but no elevated risk was observed among female alcohol drinkers. Another case-control study (355 
cases and 408 controls) found no association between alcohol drinking and esophageal cancer among women $(\mathrm{OR}=0.83$, 95\% CI: 0.22-3.09); given the limited number of female smokers, the author did not estimate the effect of smoking among women [29]. In this present analysis, we found that neither smoking nor alcohol drinking was associated with the risk of esophageal cancer among women in a Chinese population.

Some quantitative aspects of tobacco and alcohol use were demonstrated to be dose-dependently related to the risk of esophageal cancer, such as the intensity and years of consumption [2-6]. It has been suggested that the risk of smoking depends mainly on the duration of tobacco consumption rather than smoking intensity; on the contrary, the duration of alcohol drinking is less important than the weekly or daily dose of ethanol intake [30]. In our analysis, the risk of esophageal cancer was observed not only positively related to smoking duration and weekly amount of ethanol intake but also associated with smoking intensity and drinking years. Results are similar to the findings of Castellsague et al. and Fan et al. [5, 31]. The association between esophageal cancer and age at starting smoking or drinking alcohol remains inconsistent [5, 6, 31, 32], and we observed that an earlier age at starting smoking or drinking elevated the risk when compared to those who began to smoke or drink later than 30-year old, but no trend was apparent for age and cancer risk among early smokers.

In our analysis, an increased risk was observed in men both for smoking among non-drinkers and for drinking alcohol among non-smokers, confirmed that smoking and alcohol alone may play independent role in the etiology of esophageal cancer. We also found that light alcohol drinking without smoking has relatively low effect on esophageal cancer risk, whereas smoking among never drinkers increased the occurrence of esophageal cancer significantly, suggesting smoking is more strongly related to esophageal cancer than alcohol in China. The synergistic interaction when alcohol and smoking coexist has been reported previously, their joint effects are approximately multiplicative and risk in the highest consumption level may increase 130-fold [2, 5, 6]. Although a statistical interaction between smoking and alcohol drinking was observed in the present analysis, exposure to the highest joint level caused a 7.32fold risk compared to those who neither smoke nor drink alcohol, indicating less strong effects of these two wellknown factors in the high-risk Chinese population.

A beneficial reduction in the risk of esophageal cancer after cessation of smoking and alcohol consumption was observed by some previous studies, but it may take decades to decrease the risk to the level as never exposed individuals [33-37]. Several case-control studies reported that those who had stopped smoking for less than 10 years had an OR similar to that of current smokers, while quitting for 10 years or more dropped risk to that of never smokers [33-35]. Similarly, we observed that quitting smoking for less than 5 years has a similar OR $(O R=1.64)$ compared to current smokers $(\mathrm{OR}=1.54)$, while quitting more than 10 years decreased the OR to the level of never smokers (OR $=0.90)$. Different from smoking, significantly elevated ORs were observed among former alcohol drinkers, even for quitting drinking for more than 10 years $(O R=1.80)$. The consequences of drinking cessation has been studied less frequently than smoking cessation, results are more controversial, and beneficial effect has been found in some studies particularly 10 years after giving up drinking [36, 37], whereas other studies have shown either a non-beneficial effect or a higher risk among former drinkers [6, 32, 33, 38, 39]. It is possible that cases were more prone to quit drinking because of digestive tract symptoms long before cancer occurrence; thus, the higher proportion of former drinkers among cases may cause an inflated OR in this group. Another reason is that some heavy drinker cases may underreport their habit, declaring no consumption when in fact they were still drinking and consequently exhibited a higher risk than never drinkers [32]. These two reasons could also explain the increased OR among former smokers.

There are several limitations to this present analysis. Firstly, although the questionnaire had been pre-tested in some previous studies and all interviewers had been trained to explain questions to participants more clearly, the exposure level of smoking and alcohol drinking was reported by study participants without accurate measurements, and thus, subjective judgement and recall bias may exist and cause non-differential misclassification of exposures. However, the strength of the associations for esophageal cancer with smoking and alcohol consumption, particularly the dose-response trends, indicate good validity and sensitivity of our study. Secondly, when evaluating the risk of intensity and duration of smoking/ drinking, the same cutoff point was used for both men and women. Given the relatively smaller number in some categories among women, it may cause an unstable OR. However, similar results were observed when gender-specific cutoff points were used separately (data not shown). Thirdly, we were not able to determine the pathological type for all cases in this population-based study because of the low proportion of histological confirmed cases in less-developed rural areas; however, more than $95 \%$ of esophageal cancer in China are esophageal squamous cell carcinoma (ESCC) according to previous reports [40, 41].

In conclusion, our study indicates that smoking and alcohol drinking are associated with the risk of esophageal cancer among Chinese men but not among Chinese women in a high-risk population, with less strong independent and joint effects when compared with that in Western countries. Nevertheless, the elimination of these modifiable lifestyle 
risk factors should be part of the primary prevention strategy and control activities on esophageal cancer in China.

Acknowledgments The authors would like to thank the subjects for their voluntary participation, as well as the staff of local Health Bureaus and local CDCs in Dafeng and Ganyu for their assistance in fieldwork. This study is funded by Jiangsu Provincial Health Department (RC 2003090), the Graduate School VLAG at Wageningen University is also acknowledged for their financial supporting on a study fellowship.

Open Access This article is distributed under the terms of the Creative Commons Attribution Noncommercial License which permits any noncommercial use, distribution, and reproduction in any medium, provided the original author(s) and source are credited.

\section{References}

1. Demeester SR (2009) Epidemiology and biology of esophageal cancer. Gastrointest Cancer Res 3(2 Suppl):S2-S5

2. Munoz N, Day NE (1996) Esophagus. In: Schottenfeld D, Fraumeni JF (eds) Cancer epidemiology and prevention. Oxford University Press, New York, pp 681-706

3. Lagergren J, Bergstrom R, Lindgren A, Nyren O (2000) The role of tobacco, snuff and alcohol use in the aetiology of cancer of the oesophagus and gastric cardia. Int J Cancer 85:340-346

4. World Cancer Research Fund/American Institute for Cancer Research (2007) Food, nutrition, physical activity, and the prevention of cancer: a global perspective. AICR, Washington, DC, pp 60-195

5. Castellsague X, Munoz N, De Stefani E et al (1999) Independent and joint effects of tobacco smoking and alcohol drinking on the risk of esophageal cancer in men and women. Int $\mathrm{J}$ Cancer 82:657-664

6. Zambon P, Talamini R, La Vecchia C et al (2000) Smoking, type of alcoholic beverage and squamous-cell oesophageal cancer in northern Italy. Int J Cancer 86:144-149

7. Danaei G, Vander Hoorn S, Lopez AD, Murray CJ, Ezzati M (2005) Causes of cancer in the world: comparative risk assessment of nine behavioural and environmental risk factors. Lancet 366:1784-1793

8. Parkin DM, Bray F, Ferlay J, Pisani P (2005) Global cancer statistics, 2002. CA Cancer J Clin 55:74-108

9. Tran GD, Sun XD, Abnet CC et al (2005) Prospective study of risk factors for esophageal and gastric cancers in the Linxian general population trial cohort in China. Int $\mathrm{J}$ Cancer 113: 456-463

10. Wang YP, Han XY, Su W et al (1992) Esophageal cancer in Shanxi Province, People's Republic of China: a case-control study in high and moderate risk area. Cancer Causes Control 3: 107-113

11. Wang Z, Tang L, Sun G et al (2006) Etiological study of esophageal squamous cell carcinoma in an endemic region: a population-based case control study in Huaian, China. BMC Cancer 6:287

12. Jiang JM, Zeng XJ, Chen JS et al (2006) Smoking and mortality from esophageal cancer in China: a large case-control study of 19, 734 male esophageal cancer deaths and 104, 846 living spouse controls. Int J Cancer 119:1427-1432

13. Yu HP, Shi LY, Yao HY (2003) Meta-analysis on the association of esophageal cancer with smoking and alcohol drinking [Chinese]. Zhongguo Manxingbing Yufang Kongzhi Zazhi 11:1-2
14. Negri E, La Vecchia C, Franceschi S, Decarli A, Bruzzi P (1992) Attributable risks for oesophageal cancer in northern Italy. Eur J Cancer 28A:1167-1171

15. Gallus S, Bosetti C, Franceschi S et al (2001) Oesophageal cancer in women: tobacco, alcohol, nutritional and hormonal factors. $\mathrm{Br}$ J Cancer 85:341-345

16. Franceschi S, Bidoli E, Negri E, Barbone F, La Vecchia C (1994) Alcohol and cancers of the upper aerodigestive tract in men and women. Cancer Epidemiol Biomarkers Prev 3:299-304

17. Chen Z (2008) Report of the third national mortality retrospective sampling survey [Chinese]. Peking Union Medical College Press, Beijing

18. Wu M, Liu AM, Kampman E et al (2009) Green tea drinking, high tea temperature and esophageal cancer in high- and low-risk areas of Jiangsu Province, China: a population-based case-control study. Int J Cancer 124:1907-1913

19. Wu M, Zhang ZF, Kampman E et al. (2010) Does family history of cancer modify the effects of lifestyle risk factors on esophageal cancer? A population-based case-control study in China. Int $\mathrm{J}$ Cancer. doi:10.1002/ijc. 25532

20. Wu M, Zhao JK, Hu XS et al (2006) Association of smoking, alcohol drinking and dietary factors with esophageal cancer in high- and low risk areas of Jiangsu Province, China. World J Gastroenterol 12:1686-1693

21. Zhou B (2002) Predictive values of body mass index and waist circumference to risk factors of related diseases in Chinese adult population [Chinese]. Zhonghua Liuxing Bingxue Zazhi 23:5-10

22. IARC. Agents classified by the IARC monographs, vols 1-100. http://monographs.iarc.fr/ENG/Classification/Classifications AlphaOrder.pdf. Accessed 10 Sep 2010

23. Yang G, Fan L, Tan J et al (1999) Smoking in China: findings of the 1996 National Prevalence Survey. JAMA 282:12471253

24. Mackay J, Eriksen M (2002) The tobacco atlas. World Health Organization, Geneva

25. Cochrane J, Chen H, Conigrave KM, Hao W (2003) Alcohol use in China. Alcohol Alcohol 38:537-542

26. Kamangar F, Chow WH, Abnet CC, Dawsey SM (2009) Environmental causes of esophageal cancer. Gastroenterol Clin North Am 38:27-57, vii

27. Dong Z, Tang P, Li L, Wang G (2002) The strategy for esophageal cancer control in high-risk areas of China. Jpn J Clin Oncol 32(Suppl):S10-S12

28. Gao YT, McLaughlin JK, Blot WJ et al (1994) Risk factors for esophageal cancer in Shanghai, China. I. Role of cigarette smoking and alcohol drinking. Int J Cancer 58:192-196

29. Wang JM, Xu B, Rao JY, Shen HB, Xue HC, Jiang QW (2007) Diet habits, alcohol drinking, tobacco smoking, green tea drinking, and the risk of esophageal squamous cell carcinoma in the Chinese population. Eur J Gastroenterol Hepatol 19:171-176

30. Pera M, Pera M (2001) Recent changes in the epidemiology of esophageal cancer. Surg Oncol 10:81-90

31. Fan Y, Yuan JM, Wang R, Gao YT, Yu MC (2008) Alcohol, tobacco, and diet in relation to esophageal cancer: the Shanghai Cohort Study. Nutr Cancer 60:354-363

32. Vioque J, Barber X, Bolumar F et al (2008) Esophageal cancer risk by type of alcohol drinking and smoking: a case-control study in Spain. BMC Cancer 8:221

33. Launoy G, Milan CH, Faivre J, Pienkowski P, Milan CI, Gignoux M (1997) Alcohol, tobacco and oesophageal cancer: effects of the duration of consumption, mean intake and current and former consumption. Br J Cancer 75:1389-1396

34. Brown LM, Blot WJ, Schuman SH et al (1988) Environmental factors and high risk of esophageal cancer among men in coastal South Carolina. J Natl Cancer Inst 80:1620-1625 
35. Bosetti C, Gallus S, Garavello W, La Vecchia C (2006) Smoking cessation and the risk of oesophageal cancer: an overview of published studies. Oral Oncol 42:957-964

36. Rehm J, Patra J, Popova S (2007) Alcohol drinking cessation and its effect on esophageal and head and neck cancers: a pooled analysis. Int J Cancer 121:1132-1137

37. Bosetti C, Franceschi S, Levi F, Negri E, Talamini R, La Vecchia C (2000) Smoking and drinking cessation and the risk of oesophageal cancer. Br J Cancer 83(5):689-691

38. Cheng K, Duffy S, Day N, Lam T, Chung S, Badrinath P (1995) Stopping drinking and risk of oesophageal cancer. BMJ 310: 1094-1097
39. Rolon P, Castellsague X, Benz M, Munoz N (1995) Hot and cold mate drinking and esophageal cancer in Paraguay. Cancer Epidemiol Biomarkers Prev 4:595-605

40. Liu ZH (2006) The identification, regulation and function study of the differentially expressed genes in human esophageal squamous cell carcinoma. In: Kinner HK (ed) Esophageal cancer research developments. Nova Science Publishers Inc, New York, pp 1-97

41. Guo M, Zhao YD, Yang HJ, Yan XF (2008) Analysis of clinicopathological characteristics for 5406 cases of esophageal neoplasm [Chinese]. Zhonghua Zhongliu Fangzhi Zazhi 1:54-56 